\title{
ACIDIFICAÇÃO DE UM LATOSSOLO SOB PLANTIO DIRETO ${ }^{(1)}$
}

\author{
M. N. CIOTTA ${ }^{(2)}$, C. BAYER ${ }^{(3,5)}$, P. R. ERNANI ${ }^{(2,5)}$, \\ S. M. V. FONTOURA(4), J . A. ALBUQUERQUE(2) \& C. WOBETO(4)
}

\begin{abstract}
RESUMO
A aci di ficação do solo e a ciclagem de nutrientes são afetadas pelos sistemas de preparo de solo, com possíveis reflexos no desenvolvimento e rendimento das culturas. Neste estudo, avaliou-se o efeito da utilização, durante 21 anos, do sistema de plantio direto (PD) sobre características químicas das fases sólida e líquida de um Latossolo Bruno Alumínico (Guarapuava, PR), com ênfase nos componentes da acidez. No sistema PD, ocorreu uma acidificação da camada superficial do solo, evidenciada pelos menores valores de pH $(2-10 \mathrm{~cm})$ e maior concentração e saturação por Al $(6-20 \mathrm{~cm})$, em comparação ao solo em preparo convencional (PC). Por outro lado, os maiores teores de $\mathrm{Ca}, \mathrm{Mg}, \mathrm{K}$, P disponível (Mehlich-1 e Resina), carbono orgânico total e em solução, bem como a maior saturação por bases no solo em PD, contribuíram para um rendimento acumulado (39 safras) das culturas $22 \%$ superior ao obtido no PC.
\end{abstract}

Termos de Indexação: sistema de preparo de solo, característica química do solo, rendimento de culturas, solução do solo.

\section{SUMMARY: ACIDIFICATION OF A SOUTH BRAZILIAN OXISOL UNDER NO-TILLAGE}

Soil tillageaffects soil acidification and nutrient cyding and possibly causes effects on crop devel opment and yields. In this study, the long-term ( $21 \mathrm{yr}$ ) effect of the no-tillage system (NT) on soil chemical characteristics (solid phaseand solution) was evaluated in a south Brazilian Oxisol (Guarapuava, Paraná State), focussing on acidity components. NT

\footnotetext{
(1) Parte da Tese de Mestrado apresentada pelo primeiro autor ao PPG-Ciência do Solo da Universidade do E stado de Santa Catarina - UDESC. Recebido para publicação em setembro de 2001 e aprovado em julho de 2002.

(2) Professor do Departamento de Solos, Universidade do Estado de Santa Catarina - UDESC. Caixa Postal 281, CEP 88520-000 Lages (SC). E-mail: prernani@cav.udesc.br

(3) Professor do Departamento de Solos, Universidade Federal do Rio Grande do Sul - UFRGS. Caixa Postal 776, CEP 90001-970 Porto Alegre (RS). E-mail: cimelio.bayer@ufrgs.br

(4) Pesquisador da Fundação Agrária de Pesquisa Agropecuária - FAPA. Distrito de Entre Rios, CEP 85108-000 Guarapuava (PR). E-mail: sandrav@agraria.com.br

(5) Bolsista CNPq.
} 
caused an acidification process in the top soil layer, demonstrated by lower $\mathrm{pH}$ values $(2-10 \mathrm{~cm})$ and higher concentration and saturation values of $\mathrm{Al}(6-20 \mathrm{~cm})$, in comparison to soil with conventional tillage (CT). However, the highest values of exchangeable and soil solution $\mathrm{Ca}, \mathrm{Mg}$ and $\mathrm{K}$, bases saturation, availableP (Mehlich-1 and Resin), and total and solubleorganic carbon in no-tilled soil off-set thenegative effect of the soil aci dification and contri buteto a $22 \%$ higher accumulated crop yield ( 39 harvests) than under conventi onally tilled soil.

Index terms: soil tillage system, soil chemical characteristic, crop yiel ds, soil solution.

\section{INTRODUÇÃO}

A acidificação do solo é um processo natural que pode ser acelerado ou intensificado em sistemas agrícolas, principalmente pela aplicação de fertilizantes de reação ácida. Dentre os sistemas de preparo, pode ocorrer uma diferenciação na intensidade e na localização da acidez no perfil de acordo com o revolvimento, ou não, do solo (Blevins et al., 1983; Oliveira \& Pavan, 1996). No plantio direto, os fertilizantes são aplicados na linha de semeadura, na superfície do solo. Sendo assim, a dissolução dos fertilizantes fosfatados ea nitrificação dos nitrogenados amoniacais ou amídicos podem contribuir para a acidificação da camada superficial do solo, principalmente quando se consideram longos períodos de cultivo sem reaplicação de calcário, ou quando altas doses de fertilizantes são aplicadas (Blevins et al., 1983; Ernani et al., 2001). Por outro lado, o revolvimento do sol o com aração e gradagens no preparo convencional dilui a acidez originada pel os fertilizantes em toda a camada arável.

Em solo sob plantio direto, também ocorre um acúmulo de matéria orgânica, sendo a magnitude desse efeito maior na camada superficial (Bayer \& Bertol, 1999; Bayer et al., 2000a,b; Amado et al., 2001). O aumento de matéria orgânica em sol os não revolvidos decorre da diminuição da taxa de decomposição microbiana da matéria orgânica no solo pela diminuição da temperatura, aeração, aumento da cobertura do solo, agregação e do não fracionamento eincor poração dos resíduos vegetais. A magnitude do incremento varia com otipo de solo, condições climáticas e sistemas de cultura utilizados (Bayer et al., 2000a; Amado et al., 2001). Este aumento de matéria orgânica pode amenizar possíveis efeitos negativos da acidificação superficial em sol os sob sistema plantio direto pela complexação de Al (Salet et al., 1999). Além disso, nesse sistema de plantio, o acúmulo de resíduos vegetais pode diminuir a toxidez de Al a partir da lixiviação de compostos orgânicos solúveis em água, os quais atuam na complexação do Al no solo (Miyazawa et al., 1993), além do efeito positivo da adição de Ca, Mg e K destes resíduos que podem contribuir para diminuir a atividade doAl em soluçãoe, ou, aumentar a saturação por bases (Franchini et al., 1999).
O preparo do solo influi também na distribuição de nutrientes, como $\mathrm{Ca}, \mathrm{Mg}, \mathrm{K}$ e $\mathrm{P}$, no perfil do solo (Eltz et al., 1989; Muzilli, 1983). No solo sob preparo convencional, é observada uma distribuição uniforme de todos os nutrientes na camada arável, enquanto, no plantio direto, percebe-se, normalmente, um acúmulo nos centímetros superficiais, decorrente da aplicação dos fertilizantes sobre a superfície, da mineralização dos nutrientes presentes nos resíduos vegetais na superfície do solo e da maior CTC dessas camadas em virtude dos maiores teores de matéria orgânica (Bayer \& Bertol, 1999; De Maria et al., 1999). O acúmulo superficial de $P$ normalmente é mais acentuado do que dos demais nutrientes por causa de sua baixa mobilidade no solo (Bayer \& Mielniczuk, 1997).

As maior es concentrações de $\mathrm{P}$ no sol o em plantio direto e a maior saturação por bases, resultante da maior concentração de $\mathrm{Ca}$, Mg e K trocáveis no solo e, possivel mente, da complexação deAl pela matéria orgânica podem minimizar possíveis efeitos negativos da acidificação superficial do solo.

Este estudo objetivou avaliar o efeito da utilização, durante 21 anos, dosistema plantio direto sobre as características quími cas da fase sól ida e da solução de um Latossolo Bruno Alumínico, com ênfase nos componentes da acidez. O efeito do plantio direto sobre as características químicas do sol o foi avaliado em comparação ao sol o em preparo convencional, e o rendimento das culturas de soja, milho, trigo, cevada e aveia branca, num total de 39 safras, foi utilizado como um indicador fitotécnico da qualidade química do solo nos dois sistemas de preparo.

\section{MATERIAL E MÉTODOS}

O experimento foi realizado no Campo Experimental da Fundação Agrária de Pesquisa Agropecuária (FAPA), em Guarapuava (PR). Utilizou-se um Latossol o Bruno Alumínico câmbico textura argilosa $\left(610 \mathrm{~g} \mathrm{~kg}^{-1}\right.$ de argila, $320 \mathrm{~g} \mathrm{~kg}^{-1}$ de silte, e $70 \mathrm{~g} \mathrm{~kg}^{-1}$ de areia) e mineralogia da fração argila predominantemente gibbsítica (Costa, 2001). 
Originalmente, a área consistia de campo nativo e foi arada, pela primeira vez, em 1950, cultivandose trigo e arroz durante 12 anos. De 1962 a 1968, a área foi utilizada com pastagem melhorada para gado leiteiro, com trevo branco (Trifol ium repens) e gramíneas de inverno (J aster et al., 1993). Nos anos seguintes, até 1978, o sol o foi cultivado na sucessão trigo/soja (Triticum aestivum/Glicine max) em preparo convencional, com aração e gradagens.

$\mathrm{Na}$ instalação do experimento, o solo $(0-20 \mathrm{~cm})$ apresentava $\mathrm{pH}-\mathrm{H}_{2} \mathrm{O}=5,5$, teores trocáveis $\left(\mathrm{cmol}_{\mathrm{C}} \mathrm{kg}^{-1}\right)$ de Al $=0,15, \mathrm{Ca}+\mathrm{Mg}=5,7$, e K $=0,25$, saturação por Al de 2,5 \%, carbono orgânico de $28 \mathrm{~g} \mathrm{~kg}^{-1}$ e P disponível (Mehlich-1) de $5,9 \mathrm{mg} \mathrm{kg}^{-1}$ (Eltz et al., 1989; J aster et al., 1993). Como primeira cultura do experimento, cultivou-se soja na primavera-verão de 1978, a partir da correção da fertilidade do solo com 1,5 $\mathrm{Mg} \mathrm{ha}^{-1}$ de calcário e $300 \mathrm{~kg} \mathrm{ha}^{-1}$ de escória de Thomas, fertilizante que contém $19 \%$ de $\mathrm{P}_{2} \mathrm{O}_{5}$ e, por tratar-se de um resíduo da indústria siderúrgica, contém vários nutrientes em composição variada.

O experimento consistiu de cinco combinações (inverno/verão) dos sistemas de preparo convencional $(P C)$, plantio direto (PD) eescarificação (ESC): PC-PC, PC-PD, PD-PC, PD-PD, e EsC-PD, aplicadas em parcelas experimentais de $12 \times 100 \mathrm{~m}$. Entretanto, neste estudo, somente foram avaliadas as combinações PC-PC e PD-PD, as quais permitem avaliar o efeito acumulado dos sistemas de preparo sobre as características químicas do solo durante o longo período experimental (1978-1999). O sistema PC consistiu numa aração com arado de discos na profundidade de até $20 \mathrm{~cm}$, eduas gradagens, sendo uma com grade niveladora e a outra com grade de dentes. O PD foi realizado com máquinas semeadora-adubadoras adaptadas para plantio direto. A distribuição dos tratamentos em campo seguiu o del ineamento de blocos ao acaso, com três repetições.

No período de 1978-1985, cultivou-se a sucessão trigo/soja e, de 1986 a 1999, utilizou-se um sistema de rotação de culturas envolvendo aveia branca (Avena sativa), trigo, cevada (Hordeum vulgare), ervilhaca peluda (Vicia vilosa), nabo forrageiro (Raphanus sativus), soja e milho (Zea mays). Realizou-se uma mesma adubação para toda a área experimental, a qual foi baseada na cultura e nos valores médios das análises de sol o nos sistemas de preparo. Em média, a adubação na base consistiu, em kg ha-1 ${ }^{-1}$ de 24 de $\mathrm{N}, 90$ de $_{2} \mathrm{O}_{5}$ e 60 de $_{2} \mathrm{O}$, para o milho; 16 de $\mathrm{N}, 60$ de $\mathrm{P}_{2} \mathrm{O}_{5}$ e 40 de $\mathrm{K}_{2} \mathrm{O}$, para $\mathrm{O}$ trigo; 15 de N, 75 de $\mathrm{P}_{2} \mathrm{O}_{5}$ e 75 deK 20 , para a cevada, e 6 de $\mathrm{N}, 30$ de $\mathrm{P}_{2} \mathrm{O}_{5}$ e de $\mathrm{K}_{2} \mathrm{O}$, para a aveia, utilizando-se fórmulas comerciais. A adubação nitrogenada em cobertura consistiu da aplicação de quantidades de uréia equivalentes a $150 \mathrm{~kg} \mathrm{ha}^{-1}$ de $\mathrm{N}$ no milho, 40 de $\mathrm{N}$ no trigo, 30 de $\mathrm{N}$ na cevada e
30 de $\mathrm{N}$ na aveia. As doses e o manejo da adubação seguiram as recomendações de CFRS/SC (1985, 1995).

Amostras de solo foram coletadas, em abril de 1999, com auxílio de espátula, em trincheiras de $50 \mathrm{~cm}$ de profundidade. A amostragem foi efetuada nas camadas de $0-2,2-4,4-6,6-8,8-10,10-15,15-20$, 20-30 e 30-40 cm, sendo as amostras, após secas em estufa a $65^{\circ} \mathrm{C}$, moídas e passadas em peneira com malha de $2 \mathrm{~mm}$.

Avaliaram-se algumas características químicas da fase sólida elíquida do solo. Na fase sólida, foram determinados $\mathrm{pH}-\mathrm{H}_{2} \mathrm{O}, \mathrm{pH}-\mathrm{SMP}, \mathrm{Ca}, \mathrm{Mg}, \mathrm{Al}$ e $\mathrm{K}$ trocáveis, $\mathrm{P}$, e carbono orgânico total (COT). Cál cio, $\mathrm{Mg}$ e Al foram extraídos com solução de $\mathrm{KCl}$ $1,0 \mathrm{~mol} \mathrm{~L}^{-1}$ e determinados por espectrofotometria de plasma (ICP); K trocável foi extraído com solução de ácidos diluídos (Mehlich-1) e determinado por fotometria de chama; $\mathrm{P}$ foi extraído pelos métodos de Mehlich-1 e da resina trocadora de íons e determinado por colorimetria, e o COT foi determinado por digestão sulfocrômica, conforme procedimentos descritos em Tedesco et al. (1995). Os teores de H + Al foram calculados a partir dos valores de $\mathrm{pH}-\mathrm{SMP}$, segundo a equação proposta por Escosteguy \& Bissani (1999). Os resultados de COT foram corrigidos pela densidade do solo, sendo expressos na relação massa/volume. Calcularam-se a CTC efetiva e a CTC a pH 7,0, as quais foram utilizadas no cálculo da saturação por Al (m \%) e da saturação por bases (V \%), respectivamente.

Para extrair a fração líquida do solo, foram agitadas amostras de $50 \mathrm{~g}$ desolo com $50 \mathrm{~mL}$ deágua destilada, durante 15 minutos. Após uma noite em repouso, as suspensões foram transferidas para um frasco de kitazato acoplado a uma bomba de vácuo. Colocou-se uma folha de papel filtrona base do funil e obteve-se a fração líqui da após a aplicação de vácuo (Franchini et al., 1999). Cabe salientar que esse método não extrai a verdadeira sol ução do solo, mas quantifica os nutrientes solúveis numa relação solo:água destilada de 1:1, simulando, com certa aproximação, a composição da solução do solo. A fração líquida, no decorrer do texto denominada solução do solo, foi analisada em relação ao pH, condutividade elétrica, concentração de $\mathrm{Ca}, \mathrm{Mg}, \mathrm{K}$, $\mathrm{P}$ e carbono orgânico solúvel (COS). Cálcio e Mg foram determinados por espectrofotometria de plasma, $\mathrm{K}$ por fotometria de chama e $\mathrm{P}$ pel o método descrito por Murphy \& Riley (1962).O COS foi analisado por digestão sul focrômica, pelo uso de uma curva-padrão de glicose (Salet et al., 1999).

O rendimento das culturas foi avaliado em 39 safras (1978-1999), e expresso numa umidade média de $13 \%$. Apenas a ervilhaca e o nabo forrageiro não foram avaliados quanto à produção de grãos, pois estas espécies foram utilizadas na cobertura do solo e fornecimento de $\mathrm{N}$ para o milho 
em sucessão. A colheita das culturas foi realizada com automotriz numa área útil de $800 \mathrm{~m}^{2}$ $(8 \times 100 \mathrm{~m})$, a qual representa a área da parcela experimental, excluindo-se $2 \mathrm{~m}$ de cada lado como bordadura. A grande área útil avaliada contribuiu para a obtenção de baixos coeficientes de variação (6 a 15 \%) dos resultados de rendimento de grãos.

O efeito dos preparos sobre as características químicas do solo foi analisado estatisticamente por meio da análise de variância, sendo a diferença entre as médias de tratamentos avaliada pelo teste de Tukey, a $5 \%$. O rendimento médio das culturas não foi submetido à análise estatística, uma vez que não se dispõe dos resultados das repetições experimentais dos tratamentos na fase inicial do experimento (1978-1987). A relação entre variáveis de solo foi avaliada pela significância dos coeficientes de regressão polinomial.

\section{RESULTADOS E DISCUSSÃO}

\section{Acidez ativa e condutividade elétrica}

Houve uma acidificação na camada superficial do solo em PD, evidenciada pelos valores de $\mathrm{pH}$ de 0,2 a 0,4 unidades menores na camada de $2-10 \mathrm{~cm}$ (Figura 1a), em comparação ao sol o em PC. O pH no solo em PD aumentou de 4,7 para 5,1 com a profundidade, enquanto no sol o em $\mathrm{PC}$ opH foi $5,0 \mathrm{e}$ praticamente não variou nos primeiros $30 \mathrm{~cm}$ (Figura 1a). A acidificação em PD provavelmente está relacionada com o aumento da concentração el etrolítica, evidenciado pela maior condutividade el étrica (Figura 1c), e com a aplicação de fertilizantes de reação ácida, que, ao não serem incorporados, concentram na superfície do solo o efeito ácido da nitrificação do amônio (Blevins et al., 1983) e da dissolução dos fosfatos solúveis de cál cio (Ernani et al., 2001). O pH da solução do solo também foi menor no sistema PD em comparação ao PC (Figura 1b).

$A$ acidificação atéà profundidade de $10 \mathrm{~cm}$ é um reflexo do longo período (1978 a 1999) em que o solo vem sendo cultivado sem calagem. Embora essas reações também ocorram no PC, como a camada de solo até 20 ou $30 \mathrm{~cm}$ neste sistema é mobilizada anualmente pelas arações e gradagens, maior quantidade de sol o atua notamponamento da acidez. Menores valores de $\mathrm{pH}$ na camada de 0-5 e 5-10 cm do solo em PD do que em PC também foram observados por Pottker \& Ben (1998) e por Blevins et al. (1983). Entretanto, autores, tais como: Muzilli (1983), Sidiras \& Pavan (1985) e Lal et al. (1994), não verificaram diferença nos valores de $\mathrm{pH}$ entre o sistema plantio direto e o preparo convencional, o que pode estar relacionado, possivel mente, com o maior poder tampão da acidez dos solos estudados por esses autores, menor lixiviação de bases decorrente de menor precipitação pluviométrica e
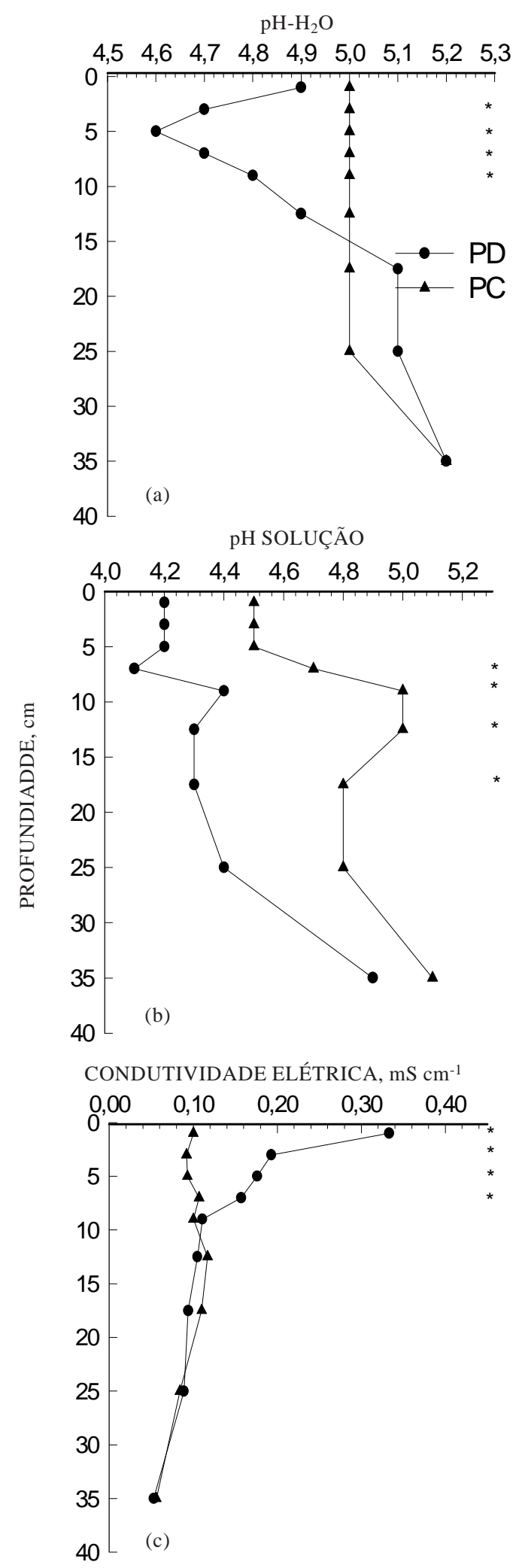

Figura 1. Valores de (a) pH- $\mathrm{H}_{2} \mathrm{O}$, (b) pH da solução e (c) condutividade elétrica no perfil de um Latossolo Bruno Alumínico submetido, durante 21 anos, aos sistemas de preparo convencional (PC) e plantio direto (PD). * significativo pelo teste de Tukey a $5 \%$. 
menor aplicação de fertilizantes com reação ácida sobre o solo, dentre outros fatores.

\section{Carbono orgânico total e solúvel}

O solo em PD apresentou maiores teores de carbono orgânico total (COT) nas camadas superficiais até $6 \mathrm{~cm}$ (Figura 2a), em comparação ao PC. Na profundidade de $0-2 \mathrm{~cm}$, a concentração de COT no sistema PD foi $35 \%$ superior à do PC, e os teores diminuíram gradativamente a partir da superfície, de $46 \mathrm{~g} \mathrm{dm}^{-3}$, na camada de $0-2 \mathrm{~cm}$, para $17 \mathrm{~g} \mathrm{dm}^{-3}$, na camada de $30-40 \mathrm{~cm}$. Esse acentuado gradiente de concentração não ocorreu no PC, onde o COT foi uniforme na camada de $0-20 \mathrm{~cm}$ (média $34 \mathrm{~g} \mathrm{dm}^{-3}$ ), e diminuiu para $24 \mathrm{~g} \mathrm{dm}^{-3}$ abaixo de $20 \mathrm{~cm}$. A manutenção de maiores teores de COT no sol o sob PD resulta da não-mobilização do sol o, onde os resíduos vegetais permanecem sobrea superfície, ocasionando uma lenta decomposição e acumulação (De Maria et al., 1999; Bayer et al., 2000a,b). Por outro lado, o revolvimento do solo no PC favorece a decomposição microbiana da matéria orgânica, por aumentar a aeração e a temperatura, bem como o fracionamento e mistura dos resíduos vegetais com o solo. Além disso, a quebra de agregados, neste último sistema, expõe a matéria orgânica protegida fisicamente no interior de agregados ao ataque microbiano (Beare et al., 1994; Six et al., 2000).

Os teores de carbono orgânico solúvel (COS, $\mathrm{mg} \mathrm{dm}^{-3}$ ) apresentaram uma relação significativa com os teores de COT $\left(\mathrm{g} \mathrm{dm}^{-3}\right)$ do solo (COS = $-34,25+3,11$ COT, $\left.r^{2}=0,68, P<0,01\right)$, sendo os maiores teores verificados nas camadas superficiais do solo em PD ( $116 \mathrm{mg} \mathrm{dm}^{-3}$ de $0-2 \mathrm{~cm}$ até $-82 \mathrm{mg} \mathrm{dm}^{-3}$ de 8-10 cm), em comparação ao sol o em PC, o qual apresentou um teor médio de $-60 \mathrm{mg} \mathrm{dm}^{-3}$, praticamente uniforme em profundidade (Figura 2b).

\section{Cátions trocáveis e solúveis}

Houve um gradiente na concentração das bases trocáveis a partir da superfície do solo em PD, enquanto o solo em PC apresentou concentrações praticamente uniformes no perfil do solo. No solo em PD, as concentrações de Ca e Mg trocáveis foram maiores até 4 e $6 \mathrm{~cm}$, respectivamente, em comparação às do PC (Quadro 1). N estes dois sistemas de preparo de solo, os valores de $\mathrm{Ca}$ atingiram 3,11 e 1,73 $\mathrm{cmol}_{c} \mathrm{~kg}^{-1}$, e os de $\mathrm{Mg} \mathrm{0,87} \mathrm{e}$ $0,47 \mathrm{cmol}_{C} \mathrm{~kg}^{-1}$, respectivamente, na média destas camadas. Na camada de $0-2 \mathrm{~cm}$, os teores de Ca e Mg no PD chegaram a ser aproximadamente duas vezes maiores do que os do PC.

Os teores deK foram mai ores na superfíciedosolo (0-2 cm) em PD. Todavia, dos 10 aos $30 \mathrm{~cm}$, mai ores teores deste nutriente ocorreram no solo em PC (Quadro 1). À semel hança do que ocorreu com o Ca e Mg, em PC os teores de K trocável não diferiram entre profundidades em toda camada de

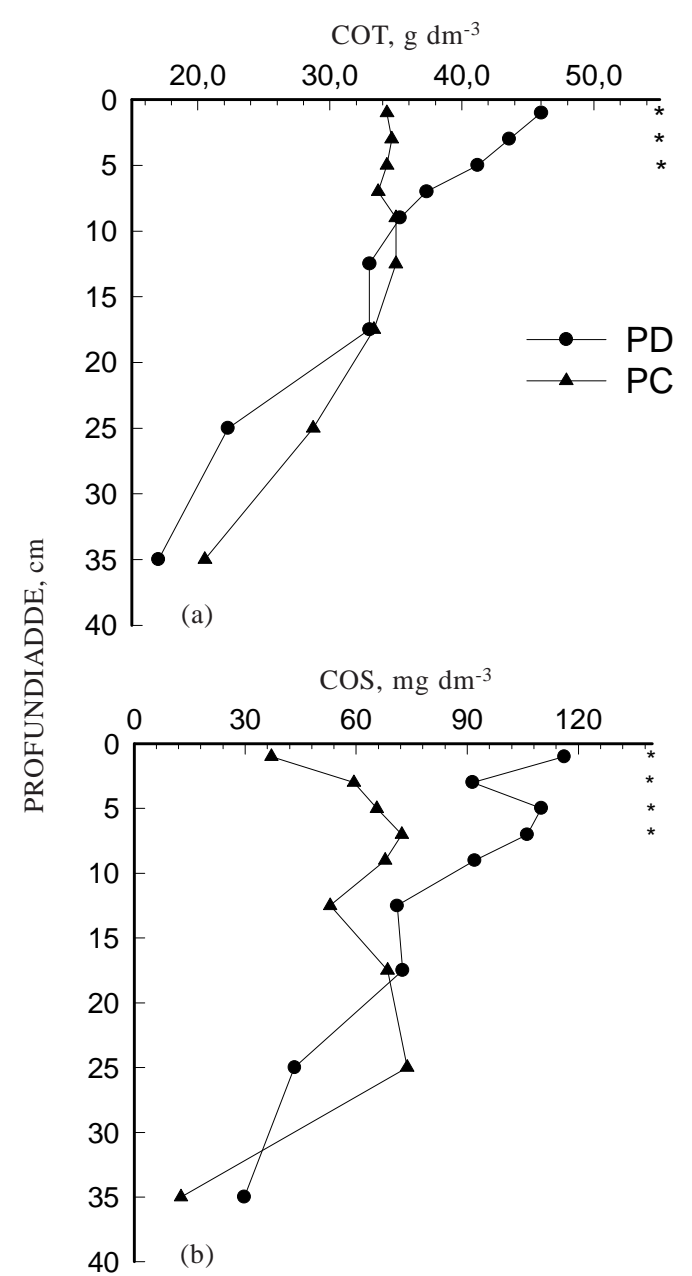

Figura 2. Teores de (a) carbono orgânico total (COT), (b) carbono orgânico solúvel (COS) no perfil de um Latossolo Bruno Alumínico submetido, durante 21 anos, aos sistemas de preparo convencional (PC) e plantio direto (PD). * significativo pelo teste de Tukey a $5 \%$.

incorporação dos fertilizantes $(0-20 \mathrm{~cm})$, porém se concentrou na superfície do PD. Uma vez que o experimento não recebia cal cário há 21 anos, o maior acúmulo das bases trocáveis na camada superficial no solo em PD resultou da ciclagem dos nutrientes contidos nos resíduos vegetais mantidos sobre o solo e da aplicação de fertilizantes sobre o solo, basicamente, fertilizantes potássicos, e fosfatos solúveis, estes por conter Ca em sua composição. Estes resultados são semelhantes aos obtidos por Eltz et al. (1989), aos sete anos da instalação deste experimento, por outros autores (Pavan et al., 1984; Ismail et al., 1994; Oliveira \& Pavan, 1996), em condições edafocl imáticas distintas.

A saturação por bases ( $\mathrm{V} \%$ ) do sol o foi inferior a $50 \%$ em ambos os sistemas de preparo (Quadro 1). No sol o em PC, a V \% foi uniforme em profundidade, apresentando um valor médio ponderado de $26 \%$. No solo em PD, a V \% alcançou valores de 44 e $31 \%$ 
Quadro 1. Concentração de Ca, Mg e K trocáveis e solúveis e saturação por bases de um Latossolo Bruno Alumínico submetido, durante 21 anos, aos sistemas de preparo convencional (PC) e plantio direto (PD)

\begin{tabular}{|c|c|c|c|c|c|c|c|c|}
\hline \multirow{2}{*}{ Profundidade } & \multicolumn{2}{|c|}{$\mathrm{Ca}$} & \multicolumn{2}{|c|}{ Mg } & \multicolumn{2}{|c|}{$\mathbf{K}$} & \multicolumn{2}{|c|}{ Saturação por base } \\
\hline & PC & PD & PC & PD & PC & PD & PC & PD \\
\hline $\mathrm{cm}$ & \multicolumn{6}{|c|}{-Trocável, $\mathrm{cmol}_{\mathrm{ckg}} \mathrm{kg}^{-1}$} & \multicolumn{2}{|c|}{$\%$} \\
\hline $0-2$ & $1,68 \mathrm{abB}$ & $3,55 \mathrm{aA}$ & $0,48 \mathrm{aB}$ & 1,19 aA & $0,29 \mathrm{aB}$ & $0,74 \mathrm{aA}$ & $25 \mathrm{aB}$ & $44 \mathrm{aA}$ \\
\hline $2-4$ & $1,78 \mathrm{abB}$ & $2,67 \mathrm{bA}$ & $0,46 \mathrm{aB}$ & $0,80 \mathrm{bA}$ & $0,28 \mathrm{abA}$ & $0,37 \mathrm{bA}$ & $26 \mathrm{aB}$ & $31 \mathrm{aA}$ \\
\hline $4-6$ & $1,78 \mathrm{abA}$ & $2,07 \mathrm{cA}$ & $0,46 \mathrm{aB}$ & $0,63 \mathrm{bcA}$ & $0,27 \mathrm{abA}$ & 0,26 bcA & $26 \mathrm{aA}$ & $27 \mathrm{bcdA}$ \\
\hline $6-8$ & $1,78 \mathrm{abA}$ & $1,77 \mathrm{cdA}$ & $0,45 a A$ & $0,56 \mathrm{cA}$ & $0,28 a b A$ & $0,19 \mathrm{cdA}$ & $25 \mathrm{aA}$ & $22 \mathrm{cdA}$ \\
\hline $8-10$ & 1,82 aA & $1,53 \mathrm{cdA}$ & $0,46 \mathrm{aA}$ & $0,51 \mathrm{cA}$ & $0,29 a B$ & $0,14 \mathrm{cdB}$ & $26 \mathrm{aA}$ & $21 \mathrm{dA}$ \\
\hline $10-15$ & 1,83 aA & $1,59 \mathrm{cdA}$ & $0,49 \mathrm{aA}$ & $0,47 \mathrm{cA}$ & 0,31 aA & $0,14 \mathrm{cdB}$ & $27 \mathrm{aA}$ & $20 \mathrm{~dB}$ \\
\hline $15-20$ & 1,85 aA & $1,72 \mathrm{cdA}$ & $0,48 \mathrm{aA}$ & $0,49 \mathrm{cA}$ & $0,25 \mathrm{abA}$ & $0,13 \mathrm{cdB}$ & $27 \mathrm{aA}$ & $23 \mathrm{cdA}$ \\
\hline $20-30$ & $1,82 \mathrm{aA}$ & $1,41 \mathrm{~dB}$ & $0,47 \mathrm{aA}$ & $0,52 \mathrm{cA}$ & $0,24 \mathrm{abA}$ & $0,10 \mathrm{~dB}$ & $26 \mathrm{aA}$ & $26 \mathrm{bcdA}$ \\
\hline \multirow[t]{2}{*}{$30-40$} & $1,24 \mathrm{bA}$ & $1,36 \mathrm{~dB}$ & $0,42 \mathrm{aA}$ & $0,55 \mathrm{cA}$ & $0,15 \mathrm{bA}$ & $0,09 \mathrm{dA}$ & $25 \mathrm{aA}$ & $29 \mathrm{bcA}$ \\
\hline & \multicolumn{6}{|c|}{ _Solução, $\mathrm{mmol}_{\mathrm{c}} \mathrm{dm}^{-3}$} & & \\
\hline $0-2$ & $0,34 \mathrm{aB}$ & 1,10 aA & $0,15 \mathrm{aB}$ & 0,58 aA & $0,20 \mathrm{aB}$ & $0,71 \mathrm{aA}$ & & \\
\hline $2-4$ & $0,27 \mathrm{aB}$ & $0,65 \mathrm{bA}$ & $0,12 \mathrm{aB}$ & $0,29 \mathrm{bA}$ & $0,18 \mathrm{aB}$ & $0,34 \mathrm{bA}$ & & \\
\hline $4-6$ & $0,27 \mathrm{aB}$ & $0,61 \mathrm{bcA}$ & $0,12 \mathrm{aB}$ & $0,26 \mathrm{bcA}$ & $0,18 \mathrm{aB}$ & $0,24 \mathrm{cA}$ & & \\
\hline $6-8$ & $0,35 \mathrm{aB}$ & $0,57 \mathrm{bcdA}$ & $0,15 \mathrm{aB}$ & 0,24 bcdA & 0,19 aA & $0,15 \mathrm{cdA}$ & & \\
\hline $8-10$ & $0,29 \mathrm{aA}$ & $0,36 \mathrm{cdeA}$ & $0,12 \mathrm{aA}$ & $0,15 \mathrm{bcdA}$ & $0,19 \mathrm{aA}$ & $0,11 \mathrm{deB}$ & & \\
\hline $10-15$ & $0,22 \mathrm{aA}$ & $0,35 \mathrm{de} A$ & $0,10 \mathrm{aA}$ & $0,13 \mathrm{cdA}$ & 0,21 aA & $0,09 \mathrm{deB}$ & & \\
\hline $15-20$ & $0,22 \mathrm{aA}$ & $0,29 \mathrm{eA}$ & $0,10 \mathrm{aA}$ & $0,11 \mathrm{cdA}$ & $0,18 \mathrm{aA}$ & $0,07 \mathrm{deB}$ & & \\
\hline $20-30$ & $0,27 \mathrm{aA}$ & $0,27 \mathrm{eA}$ & $0,09 \mathrm{aA}$ & $0,11 \mathrm{dA}$ & 0,14 aA & $0,06 \mathrm{eB}$ & & \\
\hline $30-40$ & 0,11 aA & $0,19 \mathrm{eA}$ & $0,05 \mathrm{aA}$ & $0,10 \mathrm{dA}$ & $0,08 \mathrm{aA}$ & $0,04 \mathrm{eA}$ & & \\
\hline
\end{tabular}

Letras maiúsculas comparam sistemas de preparo dentro da mesma profundidade. Letras minúsculas comparam profundidade dentro de cada sistema de preparo. Médias seguidas de mesma letra não diferem entre si pelo teste de Tukey a $5 \%$.

nas camadas de 0-2 e 2-4 cm, respectivamente, diminuindo para um val or médio ponderado de $24 \%$ na camada de $4-40 \mathrm{~cm}$. Os maiores valores de V \% na superfície do solo em PD refletem os maiores teores de Ca, Mg e K trocáveis nessa camada.

Os teores de Ca, MgeK na solução do sol o apresentaram a mesma tendência de seus teores trocáveis (Quadro 1 e Figura 3). Na camada de $0-8 \mathrm{~cm}$, o solo em PD apresentou maiores teores de $\mathrm{Ca}$ e $\mathrm{Mg}$ solúveis do que o sol o em $\mathrm{PC}$, tendo o Ca variado, em média, de 0,73 a 0,31 $\mathrm{mmol}_{\mathrm{c}} \mathrm{dm}^{-3}$, e o Mg, de 0,34 a $0,14 \mathrm{mmol}_{\mathrm{C}} \mathrm{dm}^{-3}$, respectivamente, no PD e PC. Da mesma forma, os teores de K da solução do solo (0$6 \mathrm{~cm}$ ) em PD foram aproximadamente 2,5 vezes maiores do que no sol o em PC $\left(0,43\right.$ e $\left.0,18 \mathrm{mmol}_{\mathrm{c}} \mathrm{dm}^{-3}\right)$; todavia, abaixo dos $8 \mathrm{~cm}$, ocorreu o inverso, com teores médios de 0,17 e $0,80 \mathrm{mmol}_{\mathrm{c}} \mathrm{dm}^{-3}$, respectivamente, resultado do menor teor de $\mathrm{K}$ trocável na camada subsuperficial do solo em PD.

Apesar das maiores concentrações de bases trocáveis, de maneira geral, o solo em PD apresentou maior concentração e saturação por Al em comparação ao solo em PC (Figura 4a,b). A concentração de Al variou com a profundidade no PD, tendo na camada superficial $(0-2 \mathrm{~cm})$ ocorrido a menor concentração $\left(0,81 \mathrm{cmol}_{\mathrm{C}} \mathrm{kg}^{-1}\right)$ relativamente à camada de 6 a $20 \mathrm{~cm}\left(1,54\right.$ a $\left.1,32 \mathrm{cmol}_{\mathrm{c}} \mathrm{kg}^{-1}\right)$. Por sua vez, o revolvimento do solo no sistema PC promoveu uma distribuição mais uniformedos teores deAl trocável no perfil.

É possível que a matéria orgânica tenha contribuído na complexação de Al nas camadas superficiais do solo em PD, como sugerido pela regressão múltipla que relaciona as concentrações de Al trocável e as concentrações de COT e pH do solo (Al trocável =11,295-0,168 COT - 1,95 pH, $\mathrm{r}^{2}$ $=0,58, P<0,01)$. Além da complexação pela matéria orgânica, a maior concentração de bases na sol ução contribui para diminuir a atividade doAI na solução do sol o sob PD, diminuindo o seu potencial detoxidez para as plantas (Salet et al., 1999).

\section{P disponível e $\mathbf{P}$ solúvel}

A concentração de $P$ no solo foi maior até $10 \mathrm{~cm}$ de profundidade no solo em PD, em comparação ao sol o em PC (Quadro 2). Nesta camada, a concentração de $P$ no solo em PD, determinada pelo método de Mehlich-1, foi, aproximadamente, quatro vezes maior $\left(16 \mathrm{mg} \mathrm{dm}^{-3}\right)$ do que no solo em PC $\left(3,5 \mathrm{mg} \mathrm{dm}^{-3}\right)$. A não incorporação do fertilizante ao solo no sistema PD diminui ocontato sol o-fertilizantee, conseqüentemente, a intensidade das reações de adsorção do fosfato. Acredita-se que esse fator seja responsável, em grande parte, pelos maiores teores de $\mathrm{P}$ 

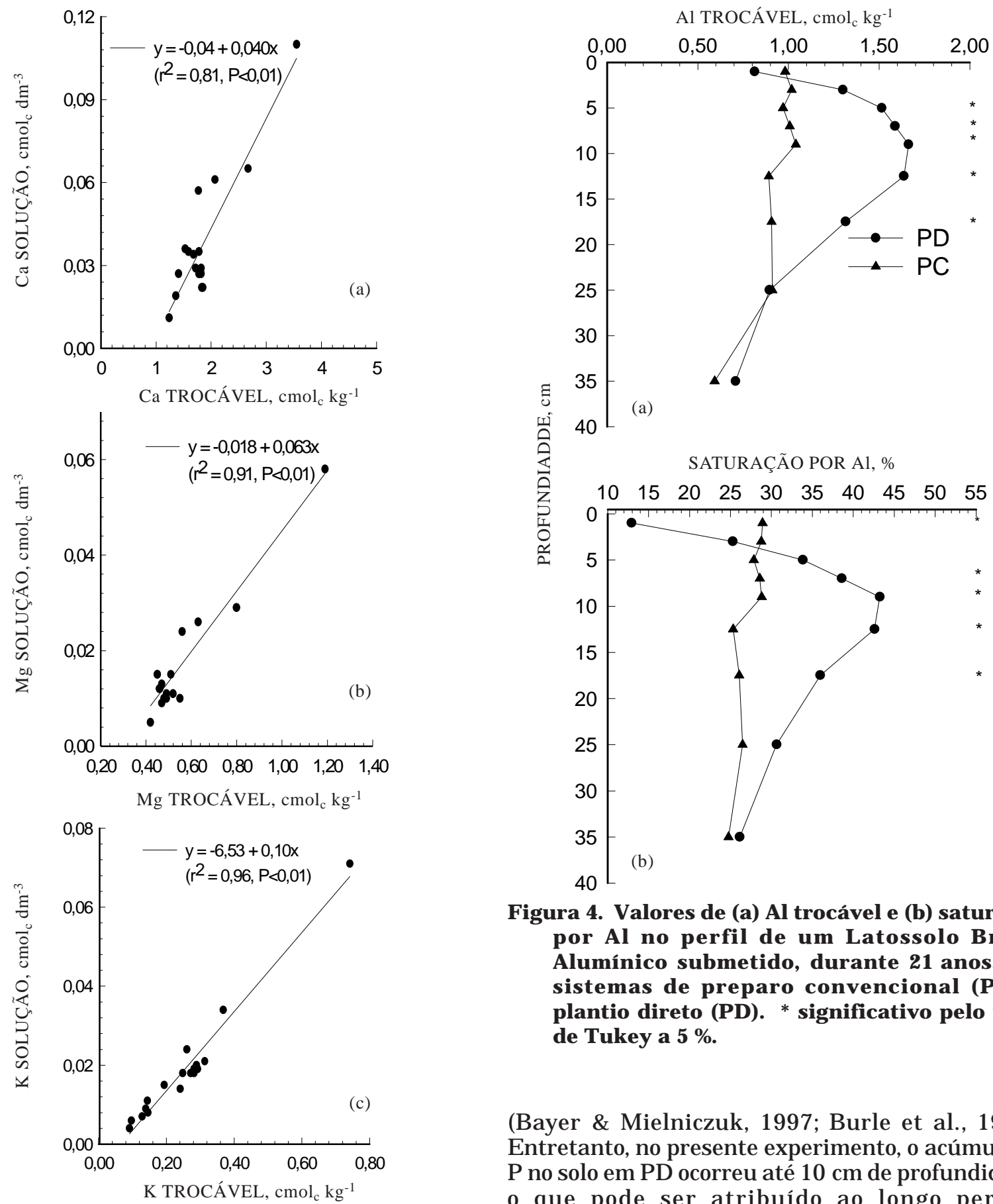

Figura 4. Valores de (a) Al trocável e (b) saturação por Al no perfil de um Latossolo Bruno Alumínico submetido, durante 21 anos, aos sistemas de preparo convencional $(P C)$ e plantio direto (PD). * significativo pelo teste de Tukey a $5 \%$.

(Bayer \& Mielniczuk, 1997; Burle et al., 1997). Entretanto, no presente experimento, o acúmulo de $\mathrm{P}$ no sol o em PD ocorreu até $10 \mathrm{~cm}$ de profundidade, o que pode ser atribuído ao longo período

Figura 3. Relação entre os teores de (a) Ca, (b) Mg e (c) $K$ trocáveis e em solução no perfil de um Latossolo Bruno Alumínico.

disponível no solo em PD, principalmente neste solo argiloso e com mineralogia predominantemente gibbsítica. Por sua vez, no sol o em PC, a incorporação dos adubos fosfatados com arações egradagens, al ém de intensificar as reações de adsorção, promoveu maior distribuição de P em todo o perfil $(0-40 \mathrm{~cm})$.

Normalmente, o acúmulo de $\mathrm{P}$ ocorre nos primeiros centímetros superficiais do solo em PD experimental (21 anos). Em áreas sob longo período em PD, a adi ção sucessiva de fertilizantes fosfatados, associada à intensa ativi dade mi crobiana na camada superficial do solo coberto por resíduos vegetais, pode favorecer a descida deste nutriente pel o movimento de compostos orgânicos de $P$ no perfil do solo (Dick, 1983). Também pode ter contribuído para o aumento de P até $10 \mathrm{~cm}$ no sol o sob PD o uso de semeadoraadubadora de linhas no inverno e verão, em todas as safras, possivel mente promovendo uma incorporação parcial dos fertilizantes a uma profundidade de aproximadamente $8 \mathrm{~cm}$. Esse efeito referente à incorporação mecânica dos fertilizantes ratifica os 
Quadro 2. Valores de P disponível (Mehlich-1 e resina) e na solução (P solúvel) de um Latossolo Bruno Alumínico submetido, durante 21 anos, aos sistemas de preparo convencional (PC) e plantio direto (PD)

\begin{tabular}{|c|c|c|c|c|c|c|}
\hline \multirow{2}{*}{ Profundidade } & \multicolumn{2}{|c|}{ P Mehlich-1 } & \multicolumn{2}{|c|}{$\mathbf{P}$ resina } & \multicolumn{2}{|c|}{$P$ solúvel } \\
\hline & PC & PD & PC & PD & PC & PD \\
\hline $\mathrm{cm}$ & & 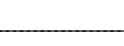 & & & 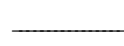 & $\underline{-}$ \\
\hline $0-2$ & $4,2 \mathrm{aB}$ & 14,5 aA & $5,6 \mathrm{aB}$ & 21,0 aA & $6,0 \mathrm{aB}$ & 27,0 aA \\
\hline $2-4$ & $3,9 \mathrm{aB}$ & 14,5 aA & $6,7 \mathrm{aB}$ & 21,0 aA & $8,0 \mathrm{aB}$ & $25,0 \mathrm{abA}$ \\
\hline $4-6$ & $3,8 \mathrm{aB}$ & 16,6 aA & $6,4 \mathrm{aB}$ & 21,8 aA & $5,0 \mathrm{aB}$ & $23,0 \mathrm{abA}$ \\
\hline $6-8$ & $4,0 \mathrm{aB}$ & 19,1 aA & $6,5 \mathrm{aB}$ & 28,0 aA & $7,0 \mathrm{aB}$ & $24,0 \mathrm{abA}$ \\
\hline $8-10$ & $4,0 \mathrm{aB}$ & 14,6 aA & $7,6 \mathrm{aB}$ & 20,5 aA & $15 \mathrm{aB}$ & 28,0 aA \\
\hline $10-15$ & 4,4 aA & $7,3 \mathrm{bA}$ & 6,4 aA & $9,6 \mathrm{bA}$ & $8,0 \mathrm{aB}$ & $16,0 \mathrm{abA}$ \\
\hline $15-20$ & $3,8 \mathrm{aA}$ & $4,4 \mathrm{bA}$ & 6,6 aA & $4,5 \mathrm{bcA}$ & $7,0 \mathrm{aB}$ & $24,0 \mathrm{abA}$ \\
\hline $20-30$ & $4,4 \mathrm{aA}$ & $1,2 \mathrm{bA}$ & $5,4 \mathrm{aA}$ & $0,4 \mathrm{cA}$ & 11,0 aA & $17,0 \mathrm{abA}$ \\
\hline $30-40$ & $1,2 \mathrm{aA}$ & $1,6 \mathrm{bA}$ & $1,6 \mathrm{aA}$ & $0,8 \mathrm{cA}$ & $8,0 \mathrm{aA}$ & $14,0 \mathrm{bA}$ \\
\hline
\end{tabular}

Letras maiúsculas comparam sistemas de preparo dentro da mesma profundidade. Letras minúsculas comparam profundidade dentro de cada sistema de preparo. Médias seguidas de mesma letra não diferem entre si pelo teste de Tukey a $5 \%$.

resultados de Eltz et al. (1989), que, aos sete anos de condução deste mesmo experimento, encontraram maiores concentrações de $P$ no solo em PD (33 $\left.\mathrm{mg} \mathrm{dm}^{-3}\right)$ do que no PC $\left(7 \mathrm{mg} \mathrm{dm}^{-3}\right)$ até $8 \mathrm{~cm}$ de profundidade.

Em relação aos diferentes métodos de análise de $\mathrm{P}$ utilizados, houve grande correlação entre as concentrações de $\mathrm{P}$ determinadas pelo método de Mehlich-1 e pelo método da resina $\left(r^{2}=0,98\right.$, $P<0,01$ ). Na solução do solo, a concentração de $P$ também foi maior no PD do que no PC, sendo a diferença verificada até à profundidade de $20 \mathrm{~cm}$. Na média da camada de $0-20 \mathrm{~cm}$, a concentração de $P$ solúvel no solo sob $P C$ foi de $8,1 \mathrm{mg} \mathrm{dm}^{-3}$, enquanto no PD foi de $23,9 \mathrm{\mu g} \mathrm{dm}^{-3}$. A maior concentração deste elemento em solução reflete também a sua menor adsorção química em sol os não revol vidos, seja o nutriente proveniente de fertilizantes minerais, seja da decomposição dos resíduos vegetais na superfície do solo.

\section{Rendimento de culturas}

No período de 1978-2000, foram avaliadas 39 safras, das quais 18 foram de soja, quatro de milho, sete de trigo, sete de cevada e três de aveia branca (grãos) (Quadro 3). A soja produziu $42 \%$ mais no sistema PD em comparação ao PC. O milho apresentou a mesma tendência da soja, com uma diferença de $22 \%$. Nas culturas de inverno, a diferença de rendimento entre os sistemas de preparo foi menor do que no verão, sendo os acréscimos no sistema PD deaproximadamente $6 \%$ no trigo, $7 \%$ na cevada e $9 \%$ na aveia branca, em comparação ao PC. Eltz et al. (1989), ao final de sete anos de condução deste experimento, já observaram superioridade no rendimento acumulado de grãos em $22 \%$ no sistema PD em comparação ao PC.
Quadro 3. Rendimento médio de culturas de inverno e verão nos sistemas de preparo convencional (PC) e plantio direto (PD)

\begin{tabular}{lrrcr}
\hline \multirow{2}{*}{ Cultura } & \multirow{2}{*}{ No safras } & \multicolumn{3}{c}{ Rendimento } \\
\cline { 3 - 5 } & & PC & PD & PD/PC \\
\cline { 3 - 5 } & & \multicolumn{3}{c}{ Mg ha $^{-1}$} \\
Soja & 18 & 1,44 & 2,06 & 1,42 \\
Milho & 4 & 6,75 & 8,25 & 1,22 \\
Trigo & 7 & 2,23 & 2,36 & 1,06 \\
Cevada & 7 & 1,93 & 2,07 & 1,07 \\
Aveia & 3 & 2,13 & 2,33 & 1,09 \\
Total & 39 & - & - & 1,22 \\
\end{tabular}

$\overline{\text { Rendimento de grãos não foi submetido à análise estatística por }}$ não se dispor de resultados referentes às repetições experimentais do período inicial deste experimento (1978-1987).

O rendimento das culturas foi inter pretado como um indicador fitotécni co das alterações químicas do solo em PD. Nesse sentido, o maior rendimento das culturas no sistema PD revela que o possível efeito negativo da acidificação do solo, evidenciado pelos menores valores de $\mathrm{pH}$ e maior concentração e saturação por Al nas camadas superficiais do solo neste sistema conservacionista de preparo, tenha sido compensado pela maior concentração de bases trocáveis, saturação por bases, disponibilidade de fósforo e por maiores concentrações de COT e COS no solo, determinando, desta forma, um ambiente químico mais favorável ao estabelecimento e desenvol vimento vegetal, em comparação ao sol o em PC. A não-ocorrência de fatores físicos do solo restritivos ao desenvolvimento vegetal, bem como as menores temperaturas do sol o no verão e o maior 
conteúdo de água no sol o em PD (Costa, 2001), pode ter contribuído para que as mel horias na quali dade química do sol o determinassem maiores rendi mentos das culturas neste sistema conservacionista de manejo do solo, em comparação ao PC.

\section{CONCLUSÕES}

1. Em plantio direto, ocorreu acidificação na camada superficial do solo, evidenciada pelos menores valores de $\mathrm{pH}$ e maior concentração e saturação por Al, em comparação ao solo em preparo convencional.

2. As maiores concentrações de $\mathrm{Ca}, \mathrm{Mg}, \mathrm{K}$ e de $\mathrm{P}$ na fase sólida e na solução, bem como os maiores teores de carbono orgânico total e solúvel, atuam na minimização do efeito negativo da acidificação do solo em plantio direto, contribuindo para a obtenção demaiores ou equivalentes rendimentos das culturas neste sistema conservacionista de manejo.

\section{AGRADE CIMENTOS}

Os autores agradecem ao Engo-Agro Sr. Franz J aster, pela instalação e acompanhamento do experimento na sua fase inicial, salientando a visão privilegiada deste profissional, cuja iniciativa pioneira trouxe grande contribuição para o avanço do entendimento e adoção de sistemas conservacionistas de manejo do solo no Sul do Brasil.

\section{LITE RATURA CITADA}

AMADO, T.J.C.; BAYER, C.; ELTZ, F.L.F. \& BRUM, A.C.R. Potencial de culturas de cobertura em acumular carbono e nitrogênio no solo no plantio direto e a melhoria da qualidade ambiental. R. Bras. Ci. Solo, 25:189-197, 2001.

BEARE, M.H.; CABRERA, M.L.; HENDRIX, P.F. \& COLEMAN, D.C. Aggregate-protected and unprotected organic matter pools in conventional- and no-tillage soils. Soil Sci. Soc. Am. J., 58: 787-795, 1994.

BAYER, C. \& MIELNICZUK, J . Características químicas do solo afetadas por métodos de preparo e sistemas de culturas. R. Bras. Ci. Solo, 21:105-112, 1997.

BAYER, C. \& BERTOL, I. Características químicas de um Cambissolo Húmico afetadas por sistemas de preparo, com ênfaseà matéria orgânica. R. Bras. Ci. Solo, 23:687-694 1999.

BAYER, C.; MARTIN-NETO, L.; MIELNICZUK, J \& \& CERETTA, C.A. Effect of no-till cropping systems on soil organic matter in a sandy clay loam Acrisol from southern Brazil monitored by electron spin resonance and nud ear magnetic resonance. Soil Till. Res., 53:95-104, 2000a.

BAYER, C.; MIELNICZUK, J .; AMADO, T.J .C.; MARTIN-NETO, L. \& FERNANDES, S.V. Organic matter storage in a sandy clay loam Acrisol affected by tillage and cropping systems in southern Brazil. Soil Till. Res., 54:101-109, 2000b.
BLEVINS, R.L.; THOMAS, G.W.; SMITH, M.S.; FRYE, W.W. \& CORNELIUS, P.L. Changes in soil properties after 10 years continuous non-tilled and conventionally tilled corn. Soil Till. Res., 3:135-146, 1983.

BURLE, M.L.; MIELNICZUK,J . \& FOCCHI,S. Effect of cropping systems on soil chemical characteristics with emphasis on soil acidification. Plant Soil, 190:309-316, 1997.

COMISSÃO DE FERTILIDADE DO SOLO - CFRS/SC. Passo Fundo, RS. Recomendações de adubação e calagem para os estados do Rio Grande do Sul e Santa Catarina. 2.ed. Passo F undo, SBCS-Núcleo Regional Sul/EMBRAPA-CNPT, 1985. 128p.

COMISSÃO DE FERTILIDADE DO SOLO - CFRS/SC. Passo Fundo, RS. Recomendações de adubação e calagem para o estado do Rio Grande do Sul e Santa Catarina. 3.ed. Passo Fundo, SBCS-Núcleo Regional Sul/E MBRAPA-CNPT, 1995. $224 p$.

COSTA, F.S. Propriedades físicas e produtividade de culturas de um Latossol o Bruno sob sistemas de manejo do solo em experimento de Ionga duração. Lages, Universidade do Estado de Santa Catarina, 2001. 98p. (Tese de Mestrado)

DE MARIA, I.C.; NNABUDE, P.C. \& CASTRO, O.M. Long-term tillage and crop rotation effects on soil chemical properties of a Rhodic Ferralsol in southern Brazil. Soil Till. Res., 51:71-79, 1999.

DICK, W. Organic carbon, nitrogen, and phosphorus concentrations and $\mathrm{pH}$ in soil profiles as affected by tillage intensity. Soil Sci. Soc. Am. J., 47:102-107, 1983.

ELTZ, F.L.F.; PEIXOTO, R.T.G. \& J ASTER, F. Efeitos desistemas de preparo do solo nas propriedades físicas e químicas de um Latossolo Bruno álico. R. Bras. Ci. Solo, 13:259-267, 1989.

ERNANI, P.R.; STECKLING, C. \& BAYER, C. Características químicas de solo e rendimento de massa seca de milho em função do método de aplicação de fosfatos, em dois níveis de acidez. R. Bras. Ci. Solo, 25:939-946, 2001.

ESCOSTEGUY,P.A. \& BISSANI, C.A. Estimativa deH + Al pelo pH SMP em solos do Rio Grande do Sul e Santa Catarina. R. Bras. Ci. Solo, 23:175-179, 1999.

FRANCHINI,J.C.; MALAVOLTA, E.; MIYAZAWA, M. \& PAVAN, M.A. Alterações químicas em solos ácidos após a aplicação de resíduos vegetais. R. Bras. Ci. Solo, 23:533-542, 1999.

ISMAIL, I.; BLEVINS, R.L. \& FRYE, W.W. Long-term no-tillage on soil properties and continuous corn yields. Soil Sci. Soc. Am. J., 58:193-198, 1994.

JASTER, F.; ELTZ, F.L.F.; FERNANDES, F.F.; MERTEN, G.H.; GAUDÊNCIO, C.A. \& OLIVEIRA, M.C.N. Rendimento de grãos em diferentes sistemas de preparo e manejo de solos. Londrina, Empresa Brasileira de Pesquisa Agropecuária, 1993. 37p. (Boletim Técnico)

LAL, R.; MAHBOUBI, A.A. \& FAUSEY, N.R. Long-term tillage and rotation effects on properties of a central Ohio soil. Soil Sci. Soc. Am. J., 58:517-522, 1994.

MIYAZAWA, M.; PAVAN, M.A. \& CALEGARI, A. efeito de material vegetal na acidez do solo. R. Bras. Ci. Solo, 17:411-416, 1993. 
MURPHY, J \& \& RILEY, J.P. A modified single solution method for the determination of phosphatein natural waters. Anal. Chim. Acta, 27:31-36, 1962.

MUZI LLI, O. I nfluência do sistema de plantio direto, comparado ao convencional, sobre a fertilidade da camada arável do solo. R. Bras. Ci. Solo, 7:95-102, 1983.

OLIVEIRA, E.L. \& PAVAN, M.A. Control of soil acidity in notillage system for soybean production. Soil Till. Res., 38:4757, 1996.

PAVAN, M.A.; BINGHAM, F.T. \& PRATI, P.F. Redistribuition of exchangeable calcium, and magnesium and aluminum following lime or gypsum applications to a Brazilian Oxisol . Soil Sci. Soc. Am. J ., 48:33-38, 1984.

POTTKER, D. \& BEN, J.R. Calagem para uma rotação de culturas no sistema plantio direto. R. Bras. Ci. Solo, 24:589597, 1998.
SALET, R.; ANGHINONI, I. \& KOCHHANN, R.A. Atividade do Alumínio na solução do solo do sistema plantio direto. R. Cient. Unicruz, 1:9-13, 1999.

SANTOS, H.P. \& TOMM, G.O. Estudo da fertilidade do solo sob quatro sistemas de rotação de culturas envolvendo trigo em plantio direto. R. Bras. Ci. Solo, 20:407-414, 1996.

SIDIRAS, N. \& PAVAN, M.A. Influência do sistema de manejo do solo no seu nível de fertilidade. R. Bras. Ci. Solo, 9:249-254, 1985.

SIX, J .; ELLIOT, E.T. \& PAUSTIAN, K. Soil macroaggregate turnover and microaggregate formation: a mechanism for C sequestration under no-tillage agriculture. Soil Biol. Biochem., 32:2099-2103, 2000.

TEDESCO, M.J .; GIANELO, C.; BISSANI , C.A.; BOHNEN, H. \& VOLKWEISS, S. Análises de solo, plantas e outros materiais. Porto Alegre, Universidade Federal do Rio Grande do Sul, 1995. 174 p. (Boletim Técnico de Solos, 5) 